\title{
Cultural Competency
}

National Cancer Institute

\section{Source}

National Cancer Institute. Cultural Competency. NCI Thesaurus. Code C94474.

The ability to understand, appreciate, and interact with persons from cultures other than one's own. 